\title{
Oxidação dos amidos de mandioca e de milho comum fermentados: desenvolvimento da propriedade de expansão
}

Oxidation of fermented cassava and corn starches: development of the expansion property

\author{
Alvaro Renato Guerra DIAS ${ }^{1 *}$, Moacir Cardoso ELIAS ${ }^{1}$, Maurício OLIVEIRA ${ }^{1}$, Elizabete HELBIG ${ }^{1}$
}

\begin{abstract}
Resumo
Amidos de mandioca e de milho comum foram fermentados em laboratório a $20^{\circ} \mathrm{C}$, sendo uma fração seca ao sol e outra oxidada com peróxido de hidrogênio e secada artificialmente, visando o desenvolvimento da propriedade de expansão. Estudou-se a fermentação em 0, 10, 30 e 50 dias, sendo a propriedade de expansão no forneamento avaliada pelo teste do biscoito e o comportamento viscoamilográfico pelo RVA. Verificou-se que a fermentação promove modificação que auxilia na oxidação dos amidos de mandioca e de milho elevando a acidez titulável do produto. O amido de mandioca fermentado oxidado com exposição solar ou com peróxido de hidrogênio pode desenvolver a propriedade de expansão, já o amido de milho comum nessas condições não tem essa capacidade. Os melhores resultados para a propriedade de expansão foram no amido de mandioca oxidado com peróxido de hidrogênio aos 50 dias de fermentação.

Palavras-chave: amido; fermentação; oxidação; expansão.
\end{abstract}

\begin{abstract}
Cassava and corn starches were fermented in the laboratory at $20{ }^{\circ} \mathrm{C}$, and a fraction was in the sun while another fraction was oxidized with hydrogen peroxide and dried artificially to develop the expansion property. Fermentation in 0, 10, 30 and 50 days was checked and the expansion property was evaluated by the baking test and viscoamilograph behavior (RVA). Fermentation was found to cause changes that help the oxidation of cassava and corn starches, increasing the product's titrable acidity. The fermented cassava starch, oxidized by exposure to sunlight or hydrogen peroxide, may develop the expansion property, but the corn starch did not display that ability under these conditions. The best results for the expansion property were obtained with cassava starch oxidized with hydrogen peroxide after 50 days of fermentation.

Keywords: starch; fermentation; oxidation; expansion.
\end{abstract}

\section{Introdução}

O desenvolvimento de novos produtos e ingredientes em panificação tem sido intensificado nos últimos anos. $\mathrm{O}$ amido fermentado de mandioca, comumente chamado de "polvilho azedo", apresenta a propriedade de expansão durante o forneamento e não contém glúten, possibilitando ser empregado em formulações para produtos especiais como os destinados a portadores de doença celíaca. Entretanto, apesar de bastante utilizado na culinária brasileira e de países da América do Sul, é um alimento que necessita ser estudado sob vários aspectos, principalmente o mecanismo de desenvolvimento da propriedade de expansão e a interferência de seus constituintes neste fenômeno, conhecimento que poderá ser aplicado em outros tipos de amidos e farinhas, como os provenientes de cereais e de outros tubérculos ${ }^{13}$.

A produção de polvilho azedo é realizada principalmente por pequenas e médias empresas que usam um processo empírico de fermentação e secagem naturais, sem controle e dependente substancialmente das condições climáticas, gerando um produto desuniforme, com problemas de contaminação e muitas vezes de péssimas características tecnológicas ${ }^{4,5,17}$.

Segundo CEREDA ${ }^{3}$, durante a fermentação do amido de mandioca desenvolve-se uma variada microflora, responsável

Recebido para publicação em 7/12/2006

Aceito para publicação em 17/5/2007 (002115)

Departamento de Ciência e Tecnologia Agroindustrial,

Faculdade de Agronomia Eliseu Maciel,

Universidade Federal de Pelotas - UFPEL,

Campus Universitário, CP 354, CEP 96010-900, Capão do Leão - RS, Brasil

E-mail:alvaro@ufpel.tche.br

*A quem a correspondência deve ser enviada

pela produção de enzimas amilolíticas e de ácidos orgânicos que podem ser responsáveis pelas propriedades funcionais do polvilho azedo.

PLATA-OLVIEDO ${ }^{14}$ estudando modificações do amido de mandioca através de ácidos orgânicos e ácido clorídrico, bem como, a forma que é realizada a secagem do produto, verificou que o tipo de ácido e a forma como é executada a secagem interferem nas características físico-químicas do amido de mandioca. Observou também, que amidos de batata e araruta, quando modificados com ácido lático, apresentaram propriedade de expansão semelhante ao amido de mandioca para a produção de biscoitos. Esta característica não foi observada com o amido de milho.

O amido nativo de mandioca seco ao sol e o amido fermentado de mandioca seco em estufa apresentam uma pobre propriedade de expansão ${ }^{8}$. No entanto, o amido fermentado de mandioca e o amido de mandioca tratado com ácidos orgânicos apresentam propriedade de expansão quando secos ao sol ou com lâmpadas de luz ultravioleta, sugerindo que a propriedade de expansão resulta de alguma modificação do amido causada pela luz ultravioleta (do sol ou das lâmpadas) na presença de ácidos orgânicos.

MESTRES e ROUAU ${ }^{11}$ não detectaram atividade amilolítica nos amidos fermentados, e ao analisarem os amilogramas produzidos pelo RVA, levantaram a hipótese do amido fermentado seco ao sol sofrer uma degradação oxidativa. No entanto, com o uso dos agentes antioxidantes, ácido ascórbico (50 g. $\mathrm{Kg}^{-1} \mathrm{de}$ amido) ou galato de propila (13-125 g. $\mathrm{Kg}^{-1}$ de amido) não foi possível evitar a queda na viscosidade máxima, com o aumento do $\mathrm{pH}$, a qual foi de aproximadamente 60 unidades RVA no 
pH 7,0. Baseados nesses resultados, os autores levantaram a hipótese da modificação química do amido provavelmente ser uma depolimeração oxidativa causada pelas ações conjuntas da fermentação e da secagem ao sol. No entanto, foi sugerida a necessidade da confirmação dessa hipótese e de estudos sobre como essa modificação poderia incrementar o poder de expansão do polvilho azedo.

PLATA-OLVIEDO ${ }^{15}$ sugeriu que a reação de oxidação promovida pela ação de luz ultravioleta do sol sobre o amido fermentado de mandioca durante a secagem seria um dos fenômenos responsáveis pelo desenvolvimento da propriedade de expansão, e esta tinha seu valor máximo a partir de 4 horas de exposição solar.

DEMIATE et al. ${ }^{6}$ modificaram amido de mandioca com ácidos e oxidantes visando o desenvolvimento da propriedade de expansão pela introdução de grupos carboxilas. Verificaram que todas as amostras oxidadas e tratadas com ácidos após a secagem na estufa apresentaram altos valores de expansão. Amostras somente acidificadas e secas ao sol também mostraram propriedade de expansão, enquanto que as secadas artificialmente apresentaram expansão muito pobre. As amostras tratadas com permanganato de potássio (soluções com $0,06 \mathrm{~N}$ a $0,01 \mathrm{~N}$ ) durante 15 minutos, seguidas de imersão em soluções com 0,79 a $1 \%\left(\right.$ p.p ${ }^{-1}$ ) de ácido lático durante 30 minutos, drenadas e secadas artificialmente apresentaram volume específico dos biscoitos em torno de $17 \mathrm{~mL} . \mathrm{g}^{-1}$. Já quando foi utilizado ácido cítrico os valores situaram-se em torno de 13 a $17 \mathrm{~mL} \cdot \mathrm{g}^{-1}$. As amostras tratadas com hipoclorito de sódio (solução com 2,4\%) durante 15 minutos e imersas em solução com ácido lático $\left(0,86 \%\right.$ p. $\left.\mathrm{p}^{-1}\right)$ apresentaram volume específico de 10 e $17 \mathrm{~mL} \cdot \mathrm{g}^{-1}$. Guando foi utilizado peróxido de hidrogênio o volume específico dos biscoitos ficou em torno de 10,8 e $17 \mathrm{~mL} \cdot \mathrm{g}^{-1}$. As amostras foram dispersas em uma solução contendo 0,05\% de FeSO4 em 15 minutos, e logo após foram drenadas e imersas em uma solução contendo $0,86 \%$ de ácido lático e $2 \mathrm{~mL}$ de $\mathrm{H}_{2} \mathrm{O}_{2}$ de concentração $30 \%$. Após 30 minutos as amostras foram recuperadas e secas. Os autores utilizando a espectroscopia FTIR conseguiram predizer a expansão do amido por ocasião do forneamento através da detecção de grupos $\mathrm{COOH}$.

DIAS $^{7}$ estudou a secagem artificial do polvilho azedo e verificou que os amidos de mandioca fermentados oxidados com hipoclorito de sódio e com peróxido de hidrogênio secos em estufa apresentavam propriedade de expansão semelhante ao amido fermentado seco ao sol. Os melhores resultados para volume, crosta e interior dos biscoitos, quando utilizado hipoclorito de sódio, foram obtidos com concentração de cloro ativo de $0,50 \%$, pH de 3,60, temperatura de $40{ }^{\circ} \mathrm{C}$ e tempo de reação de 30 minutos; já quando utilizado peróxido de hidrogênio, os melhores resultados foram com concentração do oxidante de $1,50 \%$, pH de 5,00 , temperatura de $32,5^{\circ} \mathrm{C}$ e tempo de reação de 50 minutos. Também observou que a fração solúvel interfere na oxidação do amido necessitando condições mais drásticas quando há presença da mesma. A ausência da fração solúvel em água durante a secagem artificial do amido oxidado com hipoclorito de sódio e com peróxido de hidrogênio apresentou pequena redução na propriedade de expansão, contrariamente ao observado na secagem solar, na qual ocorreu uma redução drástica desta propriedade.

Neste trabalho objetivou-se estudar a fermentação e oxidação química com secagem artificial e secagem solar do amido de mandioca e de amido de milho, visando o desenvolvimento da propriedade de expansão.

\section{Material e métodos}

\subsection{Material}

Amido de mandioca e amido de milho comum, comerciais.

\subsection{Métodos}

\section{Tratamentos}

Os tratamentos foram resultados da combinação de 2 (dois) tipos de amido (mandioca e milho) com 4 (quatro) tempos de fermentação $(0,10,30$ e 50 dias) e 2 (duas) condições de oxidação, (com peróxido de hidrogênio na concentração de 2,5\% em relação ao peso de amido (b.s.) e com exposição solar), tendo como controle os amidos sem tratamento, resultando em 18 tratamentos.

\section{Fermentação dos amidos}

Os amidos de mandioca e de milho foram submetidos à fermentação natural em laboratório, em cubas de plástico com capacidade de 20 L. Após a fermentação, cada amostra de amido foi dividida em duas frações. Uma submetida à oxidação com peróxido de hidrogênio, após a retirada da fração solúvel em água e a outra submetida à oxidação solar.

\section{Retirada da fração solúvel em água}

A retirada da fração solúvel em água foi realizada conforme metodologia descrita por DIAS ${ }^{7}$, dispersando 220 g (b.s.) de amido fermentado úmido em $500 \mathrm{~mL}$ de água destilada com agitação constante durante 10 minutos. Após, o amido foi filtrado em funil de Büchner com papel filtro de média porosidade. A operação foi realizada duas vezes, sendo que na última filtragem, após toda água ter sido retirada, realizou-se a lavagem acrescentando-se $800 \mathrm{~mL}$ de água. O controle da eficiência da operação de retirada da fração solúvel procedeuse quando os valores de acidez titulável foram inferiores a 0,9 meq de NaOH.100 $\mathrm{g}^{-1}$ de amido (b.s.) e o teor de cinzas inferior a $0,01 \%$ (b.s.).

\section{Oxidação solar}

As amostras dos amidos fermentados submetidas à secagem solar foram acondicionadas em bandejas com altura de camada de amido de no máximo $0,5 \mathrm{~cm}$, com tempo de exposição de no mínimo 8 horas, até atingirem 12\% de umidade.

\section{Oxidação com peróxido de hidrogênio}

Os amidos de mandioca e de milho fermentados desprovidos da fração solúvel em água foram oxidados com peróxido 
de hidrogênio em um reator confeccionado a partir de um béquer de vidro com capacidade de $2000 \mathrm{~mL}$, colocado dentro de um recipiente metálico e envolto por água até a metade de sua parede. A este reator foi acoplado um agitador magnético com controle de velocidade e temperatura, um termômetro de mercúrio, um potenciômetro digital com compensador de temperatura e buretas para aplicação dos reagentes.

$\mathrm{O}$ amido fermentado úmido $200 \mathrm{~g}$ (b.s.), foi disperso em $300 \mathrm{~mL}$ de água destilada, aquecido à temperatura de $33^{\circ} \mathrm{C} \mathrm{e}$ adicionado do oxidante, com controle simultâneo do $\mathrm{pH}(5,0)$, durante 50 minutos, conforme DIAS ${ }^{7}$. A aplicação dos reagentes foi executada em 1 minuto, ajustando-se o pH com soluções de ácido clorídrico e hidróxido de sódio.

Depois de atingido o tempo pré-estabelecido de reação, as amostras de amido foram retiradas do reator, filtradas em papel filtro de média porosidade em funil de Büchner, dispersas novamente em $500 \mathrm{~mL}$ de água destilada, filtradas novamente e lavadas com $800 \mathrm{~mL}$ de água destilada. O amido oxidado, filtrado e lavado adicionado da fração solúvel em água, foi seco em estufa com circulação forçada de ar a $42 \pm 2{ }^{\circ} \mathrm{C}$ até atingir a umidade de aproximadamente $12 \%$.

\section{Métodos analíticos}

A umidade foi determinada por dessecação em estufa, a $103{ }^{\circ} \mathrm{C}$, até peso constante, segundo método $\mathrm{N}^{\circ} 44-15 \mathrm{~A}$ da $\mathrm{AACC}^{1}$. A determinação de cinzas foi realizada conforme o método 08-01 da $\mathrm{AACC}^{1}$. O pH e a acidez titulável foram determinados segundo o método descrito por PLATA-OLVIEDO ${ }^{15}$. As determinações de carbonila e carboxila foram realizadas segundo o método descrito por SMITH ${ }^{16}$.

As características viscoamilográficas foram determinadas com o analisador rápido de viscosidade (RVA - Rapid Visco Analyser), usando programa Thermocline for Windows versão 1.10. Profile $=$ Standar $1^{12}$, onde a rotação inicial foi de 960 RPM durante 00:00:10 e 160 durante restante do teste. De 00:00:00 a 00:01:00 a temperatura foi de $50{ }^{\circ} \mathrm{C}$, aos 00:04:42 chegou a $95{ }^{\circ} \mathrm{C}$, permanecendo constante até 00:07:12, decrescendo até os $50^{\circ} \mathrm{C}$ aos 00:13:00, sendo ajustada a umidade das amostras para $14 \%$. Foram avaliadas as viscosidades máxima, mínima e final.

A propriedade de expansão das amostras de amido foi avaliada indiretamente através do teste do biscoito, seguindo a metodologia descrita por CEREDA ${ }^{2}$. Foi utilizada a seguinte formulação: amido, 100\%; gordura vegetal hidrogenada, $25 \%$; sal, $3 \%$; e água de 80 a $110 \%$. Para o preparo da massa o amido foi adicionado com $25 \%$ da água total e misturado durante 1 minuto com auxílio de uma batedeira. A seguir, foi adicionada uma mistura em ebulição, formada pela gordura vegetal hidrogenada, sal e $25 \%$ da água total, promovendo-se a mistura durante 3 minutos, com adição simultânea da água restante (50\%) no primeiro minuto. Após isso, a massa foi pesada em porções de 4,0 \pm 0,1 gramas e levada ao forno a $200{ }^{\circ} \mathrm{C}$ por 20 minutos. O volume específico dos biscoitos foi determinado pelo método de deslocamento de sementes de painço ${ }^{9}$ e foi expresso em mL.g ${ }^{-1}$.

\section{Resultados e discussão}

\subsection{Acidez titulável}

Durante o processo fermentativo de amidos ocorre a produção de ácidos orgânicos, tendo como conseqüência o aumento da acidez titulável. Na Tabela 1 são apresentados os valores para acidez titulável dos amidos de mandioca e de milho durante o período de fermentação.

Tabela 1. Acidez titulável dos amidos de mandioca e de milho comum durante a fermentação, após secagem em estufa.

\begin{tabular}{ccc}
\hline $\begin{array}{c}\text { Tempo de } \\
\text { fermentação (dias) }\end{array}$ & $\begin{array}{c}\text { Mandioca } \\
\text { acidez }\left(\text { meq. } 100 \mathrm{~g} \mathrm{~g}^{-1}\right)^{*}\end{array}$ & $\begin{array}{c}\text { Milho } \\
\text { acidez }\left(\text { meq. } 100 \mathrm{~g}^{-1}\right)^{*}\end{array}$ \\
\hline 0 & 0,75 & 1,75 \\
10 & 1,16 & 2,75 \\
30 & 0,55 & 1,75 \\
50 & 2,50 & 3,10 \\
\hline
\end{tabular}

*Média de 6 (seis) repetições.

Observou-se que a acidez titulável aumentou ao longo do período de fermentação, sendo maior para o amido de milho em todos os períodos avaliados. Os valores de acidez titulável obtidos no experimento foram inferiores ao encontrados por DIAS ${ }^{7}$ para o amido de mandioca que se situou em 6,71 meq. $100 \mathrm{~g}^{-1}$ de amido, o que indica uma fermentação não tão intensa, possivelmente por temperaturas amenas no período estudado, que situou-se entre 18 e $20^{\circ} \mathrm{C}$ de temperatura média diária.

\subsection{Volume dos biscoitos}

Os volumes específicos dos biscoitos são apresentados na Tabela 2.

Observou-se que o amido de milho não apresentou desenvolvimento da propriedade de expansão em nenhum tratamento. PLATA-OLVIEDO ${ }^{14}$ também observou este resultado quando tratou o amido de milho com ácido e o secou ao sol.

$\mathrm{O}$ amido de mandioca quando oxidado, mesmo sem fermentação, apresentou propriedade de expansão com volume dos biscoitos de $6,59 \mathrm{~mL} . \mathrm{g}^{-1}$. O amido fermentado a partir de 10 dias e oxidado apresentou boa propriedade de expansão, com 15,04 mL.g ${ }^{-1}$ aos 50 dias de fermentação. Entretanto, o amido fermentado seco ao sol, em todos os tratamentos, não apresentou boa propriedade de expansão, o que evidencia que o processo fermentativo foi deficiente, não promovendo uma modificação química-enzimática adequada, o que pode ser comprovado pelos baixos valores de acidez obtidos no item 3.1. Também fica descartada a hipótese de deficiência na exposição solar, pois a modificação solar a partir de 4 horas já produz o seu efeito máximo em desenvolvimento de expansão ${ }^{15}$, e no referido experimento a exposição foi de 8 horas.

DIAS $^{7}$, oxidando amido de mandioca com hipoclorito de sódio e com peróxido de hidrogênio, obteve como valores máximos de volume específico dos biscoitos 12,61 e 13,57 mL.g ${ }^{-1}$, respectivamente. Observou que a concentração do reagente, o $\mathrm{pH}$ e a temperatura de reação interferem no desenvolvimento da propriedade de expansão. 
Tabela 2. Volume específico dos biscoitos produzidos com amidos de mandioca e de milho comum, fermentados e oxidados sob duas condições.

\begin{tabular}{cccc}
\hline Amido & Tempo de fermentação (dias) & Condição de oxidação & Volume específico do biscoito (mL.g $\left.{ }^{-1}\right)^{*}$ \\
\hline Mandioca & 0 & Solar & 3,67 \\
& 10 & Solar & 7,22 \\
& 30 & Solar & 5,28 \\
& 50 & Solar & 5,86 \\
& 0 & Química & 6,59 \\
& 10 & Química & 14,99 \\
& 30 & Química & 12,36 \\
& 50 & Química & 15,04 \\
& & Sem oxidação & 2,80 \\
\hline Milho & 0 & Solar & 2,13 \\
& Solar & 2,19 \\
& Solar & 1,73 \\
& Solar & 2,07 \\
& 0 & Química & 2,76 \\
& Química & 2,73 \\
\end{tabular}

*Os resultados expressam a média de 18 (dezoito) repetições.

\subsection{Conteúdo de carbonila + carboxila}

O conteúdo de carbonila + carboxila, que expressa o total de oxidação dos amidos são apresentados na Tabela 3. Observa-se que para o amido de milho, na secagem solar, ocorreu um pequeno aumento no conteúdo de carboxila e carbonila. Já quando oxidado, o amido de milho aos 50 dias de fermentação apresentou um incremento intenso no conteúdo de carbonila e carboxila $0,341 \mathrm{CHO}+\mathrm{COOH} \cdot 100^{-1} \mathrm{GU}$ em relação ao amido sem oxidação 0,223 CHO + COOH.100-1 GU.

$\mathrm{O}$ amido de mandioca apresentou níveis mais baixos de $\mathrm{CHO}+\mathrm{COOH}$, no entanto, observou-se que com o aumento do tempo de fermentação ocorreu aumento do conteúdo de carbonila e de carboxila dos amidos, tanto na oxidação solar como na química.

Os maiores valores foram obtidos aos 50 dias de fermentação com oxidação química, o que evidencia que a fermentação promove uma modificação no amido que auxilia posterior oxidação. KUAKPETOON e WANG ${ }^{10}$, oxidaram amido de milho com $\mathrm{NaOCl}$ e observaram que o teor de amilose interferiu na extensão da oxidação. Quanto menor o teor de amilose, mais intensa é a oxidação. O que sugere que, no caso do amido de milho, deveriam ser estudados diferentes níveis de amilose para obter uma resposta mais segura quanto ao nível de oxidação e expansão.

\subsection{Viscosidade da pasta}

A análise da viscosidade da pasta de amidos expressa em grande parte as modificações ocorridas em suas propriedades reológicas. Na Tabela 4 são apresentadas as características das pastas dos amidos de mandioca e de milho fermentados ao longo de 50 dias e oxidados por exposição solar e por peróxido de hidrogênio. Observou-se que para o amido de milho, a oxidação afetou mais drasticamente a viscosidade final das pastas, ocorrendo a maior queda no tratamento com oxidação química aos
Tabela 3. Conteúdo de carbonila + carboxila dos amidos de mandioca e de milho comum, fermentados e oxidados sob duas condições.

\begin{tabular}{|c|c|c|c|}
\hline Amido & $\begin{array}{c}\text { Tempo de } \\
\text { fermentação } \\
\text { (dias) }\end{array}$ & $\begin{array}{l}\text { Condição de } \\
\text { oxidação }\end{array}$ & $\mathrm{CHO}+\mathrm{COOH} \cdot 100^{-1} \mathrm{GU}^{*}$ \\
\hline \multirow[t]{9}{*}{ Mandioca } & 0 & Solar & 0,133 \\
\hline & 10 & Solar & 0,141 \\
\hline & 30 & Solar & 0,142 \\
\hline & 50 & Solar & 0,155 \\
\hline & 0 & Química & 0,138 \\
\hline & 10 & Química & 0,145 \\
\hline & 30 & Química & 0,150 \\
\hline & 50 & Química & 0,185 \\
\hline & & Sem oxidação & 0,141 \\
\hline \multirow[t]{9}{*}{ Milho } & 0 & Solar & 0,245 \\
\hline & 10 & Solar & 0,252 \\
\hline & 30 & Solar & 0,237 \\
\hline & 50 & Solar & 0,275 \\
\hline & 0 & Química & 0,222 \\
\hline & 10 & Química & 0,226 \\
\hline & 30 & Química & 0,256 \\
\hline & 50 & Química & 0,341 \\
\hline & & Sem oxidação & 0,223 \\
\hline
\end{tabular}

*Os resultados expressam a média de 6 (seis) repetições; GU = glicose.

50 dias de fermentação. Para o amido de mandioca, observou-se que tanto a oxidação solar como a química promoveram uma queda na viscosidade final das pastas. Sendo mais intensa na oxidação química, que a partir dos 10 dias de fermentação já apresentou valores semelhantes aos observados aos 50 dias, o que coincide com o desenvolvimento pronunciado da propriedade de expansão. DIAS ${ }^{7}$, relatou que a viscosidade final da pasta de amido é bastante sensível à oxidação por peróxido de hidrogênio e ao amido de mandioca fermentado oxidado, e pode-se relacionar esta característica com o desenvolvimento da propriedade de expansão dos amidos oxidados. 
Tabela 4. Viscosidade da pasta dos amidos de mandioca e de milho comum, fermentados e oxidados sob duas condições.

\begin{tabular}{|c|c|c|c|c|c|}
\hline Amido & $\begin{array}{l}\text { Tempo de fermentação } \\
\text { (dias) }\end{array}$ & Condição de oxidação & Visc. Máxima & Visc. Minima & Visc. Final \\
\hline \multirow[t]{9}{*}{ Mandioca } & 0 & Solar & 228,67 & 76,08 & 205,25 \\
\hline & 10 & Solar & 214,58 & 97,58 & 176,83 \\
\hline & 30 & Solar & 228,58 & 66,83 & 200,25 \\
\hline & 50 & Solar & 214,58 & 107,50 & 155,00 \\
\hline & 0 & Química & 219,50 & 108,42 & 160,00 \\
\hline & 10 & Química & 197,25 & 130,00 & 97,25 \\
\hline & 30 & Química & 214,17 & 105,00 & 108,08 \\
\hline & 50 & Química & 210,50 & 149,25 & 103,75 \\
\hline & & Sem oxidação & 230,51 & 80,21 & 208,25 \\
\hline \multirow[t]{9}{*}{ Milho } & 0 & Solar & 205,33 & 63,42 & 212,50 \\
\hline & 10 & Solar & 213,08 & 56,25 & 217,50 \\
\hline & 30 & Solar & 204,58 & 69,75 & 207,83 \\
\hline & 50 & Solar & 214,58 & 75,33 & 206,17 \\
\hline & 0 & Química & 202,75 & 93,00 & 194,00 \\
\hline & 10 & Química & 199,50 & 72,08 & 205,75 \\
\hline & 30 & Química & 212,00 & 93,92 & 200,25 \\
\hline & 50 & Química & 212,83 & 97,42 & 165,75 \\
\hline & & Sem oxidação & 208,33 & 69,57 & 215,12 \\
\hline
\end{tabular}

*Os resultados expressam a média de 6 (seis) repetições.

\section{Conclusões}

A fermentação promove modificação no amido que auxilia na oxidação dos amidos de mandioca e de milho. O amido de mandioca fermentado oxidado com exposição solar ou com peróxido de hidrogênio pode desenvolver a propriedade de expansão, já o amido de milho comum fermentado e oxidado com exposição solar ou com peróxido de hidrogênio não desenvolve a propriedade de expansão. Os melhores resultados para a propriedade de expansão foram no amido de mandioca oxidado com peróxido de hidrogênio aos 50 dias de fermentação.

\section{Agradecimentos}

À FAPERGS (Fundação de Apoio à Pesquisa do Estado do Rio Grande do Sul) pelo auxílio recém-doutor que viabilizou a execução deste trabalho, à UFPel (Universidade Federal de Pelotas) e à CAPES.

\section{Referências bibliográficas}

1. AACC. AMERICAN ASSOCIATION OF CEREAL CHEMISTS. Approved methods of the american association of cereal chemists. 9a ed. St. Paul, v. 1 e 2; 1995.

2. CEREDA, M. P. Padronização para ensaios de qualidade da fécula de mandioca fermentada (polvilho azedo). I. Formulação e preparo de biscoito. Boletim da Sociedade Brasileira de Ciência e Tecnologia de Alimentos, Campinas, v. 17, n. 3, p. 287-295, 1983.

3. CEREDA, M. P. Tecnologia e qualidade do polvilho azedo. Informe Agropecuário, Belo Horizonte, v. 13, n. 145, p. 63-68; 1987.

4. CEREDA, M. P.; NUNES, O. L. G. da S.; VILPOUX, O. Tecnologia da produção de polvilho azedo. Relatório técnico-científico. Centro de Raízes Tropicais. Botucatu, São Paulo, 1995.
5. CIACCO, C. F.; CRUZ, R. Fabricação do amido e sua utilização. São Paulo, Secretaria da Indústria, Comércio, Ciência e Tecnologia do Estado de São Paulo, 1982. 152 p.

6. DEMIATE, I. M. et al. Relationship between baking behavior of modified cassava starches and starch chemical structure determined by FTIR spectroscopy. Carbohydrate Polymers, Barking, v. 42, n. 2, 2000.

7. DIAS, A. R. G. Efeito de oxidantes, de ácidos orgânicos e de fração solúvel em água na propriedade de expansão do amido de mandioca fermentado. Campinas, 2001. 149 p. Tese (Doutor em Tecnologia de Alimentos) - Faculdade de Engenharia de Alimentos, Universidade Estadual de Campinas.

8. DUFOUR, D. et al. Improving the bread-making potencial of cassava sour starch. In: DUFOUR, D.; O'BRIEN, G. M.; BEST, R. Cassava flour and starch: progress in research and development. Cali: CIRAD/CIAT, 1996. p. 133-142.

9. HSIEH, F.; HUFF, H. E. LUE, S. Twin-screw extrusion of sugar beet fiber and corn meal. Lebensmitttel Wissenschaft und Tecnologie, London, v. 24, n. 6, p. 495-500, 1991.

10. KUAKPETOON, D.; WANG, Y. Structural characteristics and physicochemical properties of oxidized corn starches varying in amylase content. Carbohydrate Research, v. 341, n. 11, 2006. p. 1896-1915.

11. MESTRES, C.; ROUAU, X. Influence of natural fermentation and drying conditions on the physical characteristics of cassava starch. Jornal of the Science of Food and Agriculture, London, v. 74, n. 2, p. 147-155, 1997.

12. NEWPORT CIENTIFIC. Operation manual for series 3: Rapid visco analyser using Termocline for Windows. Warriewood, june, 1995. 92 p. (catálogo).

13. PEREIRA, J. et al. Féculas fermentadas na fabricação de biscoitos: estudos de fontes alternativas. Ciência e Tecnologia de Alimentos, Campinas, v. 19, n. 2, p. 287-293, 1999.

14. PLATA-OLVIEDO, M. S. V.; Efeito do tratamento ácido nas propriedades físico-químicas e funcionais do amido de 
mandioca. Campinas, 1991. 135 p. Tese (Mestre em Tecnologia de Alimentos) - Faculdade de Engenharia de Alimentos, Universidade Estadual de Campinas.

15. PLATA-OLVIEDO, M. S. V.; Secagem do amido fermentado de mandioca: modificação química relacionada com a propriedade de expansão e características físico-químicas. Campinas, 1998. 114 p. Tese (Doutor em Tecnologia de Alimentos) - Faculdade de Engenharia de Alimentos, Universidade Estadual de Campinas.
16. SMITH, R. J. Caracterization and analysis of starchs. In: WHISTLER, R. L.; PACHALL, U. F. Starch: chemistry and tecnology. New York: Academic Press, 1967. v. 2: Characterization and analysis of starches, p. 620-625.

17. WESTBY, A.; CEREDA, M. P. Production of fermented cassava starch (polvilho azedo) in Brazil. Tropical Science, London, v. 34, n. 2, p. 203-210; 1994. 